\title{
Understanding the Psychosocial Processes of Physical Activity for Individuals with Severe Mental IIIness: A Meta-Ethnography
}

\author{
Andrew Soundy ${ }^{1}$, Thomas Kingstone ${ }^{2}$ and Pete Coffee ${ }^{3}$ \\ 1 University of Birmingham, Birmingham, \\ ${ }^{2}$ Freshwinds Charity, Birmingham, \\ ${ }^{3}$ School of Sport, University of Stirling \\ 1,2England \\ ${ }^{3}$ Scotland
}

\section{Introduction}

Physical activity can benefit individuals with severe mental illness (SMI) (Richardson et al., 2005). The benefits of physical activity for individuals with SMI are threefold: psychological, social and physical. Psychologically, patients can experience mood elevating effects, reduced anxiety, improved concentration, increased self-esteem and reduced psychiatric symptoms like voices (Faulkner \& Biddle, 1999). Socially, co-patients in the physical activity setting can motivate, support and encourage interaction (Fogarty \& Happell, 2005), facilitating the development of a positive social identity. Physically, patients can combat a significant side effect of anti-psychotic medication such as weight loss (Faulkner et al., 2003).

Despite individuals with SMI understanding that there are benefits from engaging in physical activity, many have limited confidence in their ability to exercise and often perceptual biases (e.g., concerns generated from self-presentation, negative interpretaion of an interaction) can act as barriers in new and unknown settings (Soundy et al., 2007). A perceived inability to exercise, coupled with a lack of social support can lead to a further reduction in exercise participation and, potentially, permanent withdrawal from exercise (Ussher et al., 2007). Thus, there are (a) barriers that affect the initiation of exercise, as well as (b) barriers that prevent the adoption of a more physically active lifestyle. In support, a recent Cochrane review (Gorcyznski \& Faulkner, 2011) has called for research to develop further understanding into how best to help patients with SMI begin and continue to exercise.

Whilst some initial understanding has been provided regarding the initial engagement in physical activity, further information is needed to illustrate how experiences of physical activity vary. To this end, research is needed to consider and illustrate the psychosocial barriers and facilitators to activity in the adoption of exercise, but also in the long term maintenance of activity. This has been illustrated, although not comprehensivly evaluated, in previous research: In some research this is explicitly adressed, for example, Carless (2007) considers physical activity as phases requiring support when beginning (awareness raising) and during (engagement and practical facilitation) activity. Other research implictly addresses this; for example, Raine et al., (2002) consider the engagement of exercise in community and illustrate the experience of inititating and maintaining activity. It is clear, 
however, that barriers and facilitators to activity are likely to change across the lifespan of engagement in physical activity. In order to generate a greater understanding of this topic and of the processes involved, considerable detail of the experience of patients with SMI is required. Previous studies that detail the experience of community based activities provide this information. A qualitative approach that explores and reports on individual experiences across physical activity interventions may be best placed to forge this understanding. The process, phases and current understanding of introducing physical activity has been gauged by a number of well considered qualitative studies (Carter-Morris \& Faulkner, 2003; Carless, 2008; Carless \& Douglas, 2004;2008a;2008b; Carless and Sparkes, 2008; Crone, 2007; Faulkner and Sparkes, 1999; Shiner et al., 2008; Soundy, 2007). However, to the best of the authors' knowledge there is currently no review that synthesises and proposes advancements based upon this important and valuable information.

\section{Purpose}

Exercise and physical activity have a clear role in alleviating the secondary symptoms of SMI, such as low self-esteem and social withdrawal (Faulkner, 2005). This chapter provides some suggestions of the underpinning mechanisms by considering psychosocial factors (e.g. a sense of autonomy, self-efficacy, social support, task competency and distraction) that change as a result of participation (Mutire, 2003). Barriers and facilitators to activity are present both during the initiation phase of activity and within a maintenance phase of activity. This chapter will consider how psychosocial factors impact on barriers and facilitators to activity when patients with SMI (a) initially engage in physical activity and (b) seek to develop and sustain a physically active lifestyle.

\section{Methods}

We used a meta-ethnographic approach, as defined by Noblit and Hare (1988), and more recently Campbell et al (2003) and Weed (2008). The approach involves selecting relevant empirical studies to be synthesised, reading them repeatedly and noting down key concepts. These key concepts become the raw data for the synthesis. The synthesis of the results and discussion of empirical research studies is conducted with the purpose of identifying a unique vision and interpretation of literature. But as Weed (2008) notes, the purpose of the review is not to find the truth; rather, it is to find 'a truth'.

Traditionally, the method of a meta-ethnography involves a seven stage process (Campbell et al., 2003; Noblit \& Hare, 1988; Weed, 2008). Stages 1 and 2 involve getting started and sampling: This meant obtaining qualitative studies that consider the psycho-social processes involved with initiating and developing a physically active lifestyle. A search of the literature was conducted by the primary author. The author undertook an electronic search in December 2010 of CINAHL, AMED, EMBASE and MEDLINE databases using key words related to physical activity (EXERCISE, SPORT, PHYSICAL ACTIVTY), mental health (SEVERE MENTAL ILLNESS, SCHIZOPHRENIA), and the type of methodology used in each study (QUALITATIVE, IN DEPTH, UNSTRUCTURED OR SEMI STRUCTURED INTERVIEWS). Key authors in the area were contacted and several journals that related to this area were also searched including: Journal of Mental Health, Psychiatric Services, E British Journal of Psychiatry. In addition to this one key author (Dr D Carless) was contacted by email for details of his current research. 
Following this search, thirteen studies were identified. This is in line with similar types of review articles ( e.g., Campbell et al (2003) used 7, Malpass et al (2009) used 16, Soundy et al (2011) used 10). In order to create a range of studies that would be most comparable, appropriate for the aims of the research and useful within this analysis, a set of screening questions and standards were applied during the initial reading of the articles. Three key screening questions were employed: 'Does this paper report empirical findings from qualitative research and did that work involve both qualitative methods of data collection and an inductive method of analysis?', 'Is this research relevant to the synthesis topic?' and 'Does this work provide a distinct contribution to the analysis above and beyond the collective findings?' The inclusion criteria included the following: Each study needed to be reported in a peer review journal and written in english. The findings from each study needed to be generated from a specific sport or exercise intervention. The exercise or physical activity had to be undertaken outside the patient's mental health day centre. Data from each study had to be generated using empirical qualitative data that was non-fiction. Finally, each study had to present separate results and discussion sections so the correct meta-ethnographic analysis could be undertaken; without both sections the review could not be completed.

This meant the following studies were excluded: Carless and Douglas (2008a) because a deductive approach was used in their analysis; Carless and Sparkes (2008) because a lack of a discussion meant that second order interpretations could not be undertaken and this may have also limited third order interpretations; Carless (2008) because the study referred to a life history rather than a specific sport or exercise process or intervention; Carless and Douglas (2008b) because the study presented case studies and lacked an analytical consideration of the literature; Douglas and Carless (2010) because the study was a fictional tale; and, Soundy (2007) because it formed part of a PhD thesis and was not published. Eight studies were selected to be used within the meta-ethnography and included: Carless (2007), Shiner et al. (2008), Crone (2007), Fogarty and Happell (2005), Faulkner and Sparkes (1999), Carter-Morris and Faulkner (2003), Carless and Douglas (2004), and Crone and Guy (2008). Our exclusion criteria should not be interpreted as suggesting any devaluation of the excluded research; in fact, we have used our discussion to take account of their findings.

Similar to Campbell et al. (2003), we used stages 3 and 4 to read the selected relevant empirical studies repeatedly and note down key concepts as they began to emerge. The key concepts generated from individual studies were examined in relation to other studies. We used tables and grids to help in this and to display themes and concepts (Atkins et al., 2008; Campbell et al., 2003). In other words, we summarised and wrote commentary on the results and discussion sections of each article. The first order constructs considered the results of the studies and the second order constructs considered the discussion section of the studies (these tables can be obtained from the first author upon request).

During stage 5 we examined the reciprocal and refutational relationships between studies and examined how we could further existing knowledge found in any individual study (Britten et al., 2002; Van Manning et al., 1988). Noblit and Hare (1988) refer to this as a line of argument synthesis. In essence, we conducted a thematic analysis on our findings through summarising the first and second order concepts. This approach allowed us to maintain the language used in each study while creating new metaphors within the synthesis (Doyle, 2003). During stage 6 we created synthesised translations or third order constructs. We achieved this by examining our key themes generated from the first and second order interpretations along with the idiomatic interpretation and considered how the themes, ideas, metaphors and comments illustrated a process of activity from the onset. This included two issues as discussed above: (1) 
increasing uptake/initial engagement in exercise, and (2) how to successfully maintain longterm engagement in exercise. Stage 7 involved presenting the results.

\section{Results}

Three primary themes are presented within the first and second order interpretations: (1) psychological attributes, (2) barriers, and (3) facilitators. Finally, we consider the process of activity involvement, this is represented by two third order themes (1) the uptake of exercise (2) the prolonged engagement in exercise. The purpose of this was to allow the analysis to clearly represent the primary aims of our research.

\subsection{Psychological attributes}

The psychological attributes theme included aspects of the physical activity or exercise setting that influenced the experience of participants. The sub-themes generated included identity, and dependency, control and autonomy.

\subsubsection{Identity}

Establishing a new identity (such as a footballer; Carter-Morris and Faulkner, 2003) or recreating an identity (restarting a previous interest; Carless and Douglas, 2004) were integral aspects of participating in a new sport or activity. Intially, this is something that could draw patients towards the activities, because it allowed them to consider or project their future self. Through activity, patients could consider and be associated with positive identities, possibly past selves (Carless, 2007). This gave patients a sense that they could get back to their old self (Forgarty \& Happell, 2005) and obtain previously lost feelings, experiences and interactions. This represented a resumption of being 'normal', obtaining normality, or being restored to a past identity (Carless, 2007). This was important in drawing the patients towards the exercise.

Patients were inspired by the nature, motivation and knowledge of other patients within the activity or sports setting (Crone, 2007). The group activity provided a time for sharing personal experiences and this helped provide a sense of unity with others in the group (Crone, 2007). In addition to this the new relationships formed within the activity setting helped develop patients' identities (Shiner et al., 2008): Belonging to an exercise or sports activity provided opportunity for patients to develop a sporting or exercise identity, since most discussions within the setting focused towards this (Carter-Morris \& Faulkner, 2003). This process of sharing and engaging with others in turn influenced patients' attitudes towards fitness and motivation for activity (Fogarty \& Happell, 2005).

A patient's identity would best be maintained following positive and successful activity or exercise experiences. These experiences helped develop a patient's identity within the group and this also helped challenge their identity as a service user (Carter-Morris \& Faulkner, 2003). The patient's identity could extend to a particular identity within the group and a meaningful social role (Carless, 2007; Carter-Morris \& Faulkner, 2003). This included patients who were given responsibility for a group (e.g., a person who organised travel arrangements) or a specific role in the activity (e.g., the captain of a team). Following regular or maintained engagement the patient's athletic identity could be transferred from the group setting into other situations such as their day centre and this in turn could influence other users at these locations (Fogarty \& Happell, 2005). Often this occurred because the activity provided a positive topic of conversation when reflecting on their day's achievements (Carless \& Douglas, 2004). 


\subsubsection{Dependency, control and autonomy}

Activity developed autonomy (Carless, 2007) through providing a sense of achievement, satisfaction (Crone \& Guy, 2008), empowerment and perceived confidence (Fogarty \& Happell, 2005; Sparkes \& Faulkner 1999). In regard to initial engagement in exercise, prior knowledge, including benefits, joy or contentment of activity was instrumental to decisions (Crone, 2007). The interventions in themselves gave the service user opportunity to think about future activities (Fogarty \& Happell, 2005). Goals towards activities varied from becoming independent and autonomous in the community (Shiner et al., 2008) to undertaking a normalising activity (Carter-Morris \& Faulkner, 2003). For others, activity provided a chance to change environments (Faulkner \& Sparkes, 1999). Being associated with an athletic identity gave patients a sense of certainty and an idea of who they could become. This in itself provided a great reason for attending, but also provided a sense of empowerment and autonomy to the service users.

Autonomy was assisted by the patients being able to associate themselves with the activity and taking responsbility for the achievement gained (Carless, 2007; Carless \& Douglass, 2004). Thus, through actvity, patients could become less dependent on others and perceive greater control in social settings, such as community sport or exercise environments (Carless, 2007). Autonomy was also created within the activity session through support from others. This was achieved because patients were able to choose when and if they revealed information about themselves (Faulkner \& Sparkes, 1999). The exercise group provided a stable and non intrusive topic of conversation that was a natural part of the activity. Thus, they didn't have to talk about aspects of themselves that they did not want to disclose. The sense of having a choice to disclose information in a non pressured or judging environment helped the possibility of a patient returning to the setting and maintaining exercise.

\subsection{Barriers}

The barriers theme included aspects related to preventing successful uptake and maintenance of activity. The sub-themes generated included location, access and finances, medication and symptom change, social support and cognitive.

\subsubsection{Location, access and finances}

Patients were prevented from engaging in activity if the location of the activity was too far away or inaccessible (Shiner et al., 2008). However, some patients found that other activities 'got in the way' of the physical activity program; for example, daily chores (Crone, 2007). Thus, both the location of activity and the timing of the activity may prevent patients with SMI from taking-up exercise. Almost unanimously across the studies activity was prevented by financial cost (Carless, 2007; Carless \& Douglas, 2004; Crone, 2007; Crone \& Guy, 2008; Shiner et al., 2008). Activities such as walking could be recommended as a low cost alternative (Fogarty \& Happell, 2005). If the tangible, emotional or esteem support following the completion of research was not continued then the possibility of patients maintaining activity long-term could be severely diminished (Faulkner \& Sparkes, 1999).

\subsubsection{Medication and symptom change}

Medication had an influence on all patients (Crone \& Guy, 2008); it often influenced their level of drowsiness, motivation and could slow patients down, taking the 'shine' off their ability to undertake exercise or physical activity (Carter Morris \& Faulkner, 2003). One of 
the biggest factors that influenced participation was changes in symptoms (Carless, 2007) or a fluctuating medical status (Shiner et al., 2008). One consequence of this was the need to allow patients to withdraw (Crone, 2007), even though withdrawal is generally considered undesirable (Carless \& Douglas, 2004). In other words, patients' medication and symptoms interacted to cause a universal barrier against the uptake and maintenance of activity; this meant consistent and sustained engagement in exercise was unlikely.

\subsubsection{Social support}

In order for patients to initiate activity, social support was essential. However, the wrong type of support contributed to increased resistance towards activity engagement. For example, resistance to exercise increased when little support or empathy was expressed by health care professionals in regard to the negative side effects of medication (Carter-Morris \& Faulkner 2003), or when health care professionals had low expectations (Carless \& Douglas, 2004). If patients are not encouraged by friends and family (Crone, 2007) they are unlikely to initiate or maintain exercise. A lack of consistency of support through the physical activity process (Carless, 2007) can act as a barrier to maintaining activity. This may be because of the feelings of being isolated. Social support can become problematic if support is dependent on one or few people involved with activity or at the end of the activity program where no further provision for support has been accounted for (Faulkner \& Sparkes, 1999).

\subsubsection{Cognitive}

The patient's cognitions during activity had an important influence on activity attendance. These cognitions often occurred in new situations where patients experienced a lack of personal control (Carless, 2007) due to the unknown or uncertainty of a situation (Crone, 2007). Barriers could be created within settings (Carless \& Douglas, 2004); for example, the confidence of the patients could be tested in a 'new' situation that might be perceived as threatening (Faulkner \& Sparkes, 1999) or could be lower as a result of the illness (Shiner et al., 2008). Additionally, some patients did not like competitive circumstances (Carless \& Douglas, 2004). If patients did not want to participate they could experience an increase in their symptoms for example, voices multiplying (Faulkner \& Sparkes, 1999). Alternatively, the patients' symptoms, moods or emotions could prevent them from exercising (Shiner et al., 2008). As such, changes to a patient's identity, mood and emotions, and motivation for activity can take a long time to be developed. Carless (2007) suggests such a process can take years. Thus, experiencing or reflecting negative experiences may be a consistent barrier to patients initiating and maintaining activity.

\subsection{Facilitators}

The facilitators theme included aspects related to successful uptake and maintenance of the activity. The sub-themes generated included location, positive experience, physical and psychological benefits, and social support.

\subsubsection{Location}

The location provided a patient with a new situation and a chance to grow and express themselves. Patients valued the chance to leave their normal residence (Faulkner \& Sparkes, 1999) and engage in the wider community (Carter-Morris \& Faulkner, 2003). Patients suggested that there was a sense of excitement in trying a new activity or in seeing new 
places (Crone, 2007). For some patients, the travel and scenery provided enjoyment and the activity could represent something to look forward to and be associated with (Carless, 2007). Successful experiences were required in order to maintain activity.

\subsubsection{Positive experience}

Various conditions impacted on a patient's ability to initiate exercise. Patients suggested that motivation comes from actually doing something (Carless, 2007) or breaking from a stagnant routine (Faulkner \& Sparkes, 1999); at the most basic level, doing something was better than doing nothing (Crone \& Guy, 2008). Some patients like to start slowly when engaging with exercise (Carless \& Douglas, 2004); on the other hand, some wanted a chance to push themselves (Forgarty \& Happell, 2005). This 'choice' aided their confidence and competence (Carless, 2007) and it meant patients created memorable experiences (Crone, 2007). Thus, the patients could be excited and hopeful about a new experience, but required a choice of how to engage with the process from the uptake activity.

The key process required for the maintenance of activity was if the patient found the experience of undertaking physical activity to be rewarding. Patients experienced a valued sense of achievement in being able to reflect on an activity and in being associated with it (Carless, 2007; Crone \& Guy, 2008). Exercise provided a distraction from voices, or something that provided assistance in controlling voices (Faulkner \& Sparkes, 1999), together with helping to prevent social withdrawal (Carter-Morris \& Faulkner, 2003). The physical activity provided patients with some form of comfort towards a goal and sense of control (Faulkner \& Sparkes, 1999) or responsibility about an activity (Carless \& Douglas, 2004). Simply put, exercise engagement helped patients progress from not feeling able to respond or challenge their illness to feeling more able to incorporate physical activity alongside it (Crone, 2007).Thus, a goal that can be established by and through activity is for a patient to become more autonomous and independent.

\subsubsection{Physical and psychological benefits}

Following activity consistent psychological changes were reported by many studies, including mood elevating effects, anxiety reducing effects, improved concentration, increased self esteem and social competence (Faulkner \& Sparkes, 1999; Crone \& Guy, 2008). Exercise and sport also provided an opportunity to unwind, reducing stress levels and promoting a sense of calmness (Faulkner and Sparkes, 1999; Carless \& Douglas, 2004), leading to greater motivation and enjoyment (Fogarty \& Happell, 2005). Patients also had a better body image (Faulkner \& Sparkes, 1999). Exercise may also benefit a patient's psychotic symptoms and delusional belief systems, and also reinforce a more positive version of reality (Faulkner \& Sparkes, 1999; Carter-Morris \& Faulkner, 2003). With more exposure to activity, patients could also benefit from a decrease in anxiety towards community involvement (Shiner et al., 2008).

Physiological changes were also reported, including positive bodily change (Carless, 2007), better sleep (Crone, 2007; Faulkner \& Sparkes, 1999), better health and well-being, increased fitness and weight loss (Forgarty \& Happell, 2005), and increased energy levels (Crone \& Guy, 2008; Faulkner \& Sparkes, 1999). There were also changes in other aspects of well being such as better hygiene, seeking out opportunities for counselling, and taking the initiative to acquire information for themselves to engage further in community activities (Faulkner \& Sparkes, 1999). Patients that can experience even some of these psychological or physiological changes will clearly have a greater chance of maintaining activity 


\subsubsection{Social support}

Social support is central to the uptake and prolonged engagement in physical activity. Before the physical activity has been initiated the social needs of patients have to be considered. To ensure the most productive uptake of physical activity all staff are required to provide individualised and structured support for a patient (Forgarty \& Happell, 2005); for instance, informing a patient of who was leading the activity session (Crone \& Guy, 2008). It was important that staff did not place expectations on patients, particularly if a patient was unfit (Fogarty \& Happell, 2005). Therapists were required to encourage patients in overcoming motivational barriers, be knowledgeable about sport, as well as being sensitive and supportive through the activity process (Crone, 2007; Crone \& Guy, 2008; Shiner et al., 2008). All interaction with patients had to be initiated in a safe and comfortable way (Faulkner \& Sparkes, 1999). There was no need or request for staff at the activity or sports setting to discuss a patient's mental illness, symptoms or problems. Support revolved around encouraging engagement and creating positive experiences for patients. It was important to be with others and share experiences (Crone, 2007). Health care professionals that supported the program acted as gatekeepers of it (Crone, 2007; Crone \& Guy, 2008). In essence, to ensure uptake of exercise patients needed to feel they were entering a known, safe and supporting environment.

During the physical activity experience social support acted as a foundation for prolonged engagement. Social time had to be a part of any physical activity setting for service users (Carless \& Douglas, 2004; Faulkner \& Sparkes, 1999). Known and trusted friendships developed between staff and patients (Carless, 2007; Carter-Morris \& Faulkner, 2003) and in other studies a training partner provided support and encouragement (Forgarty \& Happell, 2005). These friendships could be associated with changes in the patient's symptoms (Shiner et al., 2008; Faulkner \& Sparkes, 1999). The cohesive nature of the exercise group helped to encourage a patient's interest and ongoing activity (Fogarty \& Happell, 2005); friendships facilitated positive cognitions and attitudes towards exercise (Faulkner \& Sparkes, 1999), and enhanced the possibility of further and prolonged engagement.

Following successful activity participation, exercise or sport became an avenue for conversation and interaction (Carter-Morris \& Faulkner, 2003), and there was enjoyment in spreading the word about participation in an activity (Carless \& Douglas, 2004). The social interaction helped increase social confidence (Crone, 2007; Crone \& Guy, 2008) and provided initiation for life improvements (Faulkner \& Sparkes, 1999). Thus, the development of patient's social skills can be seen as part of a productive process that helps reinforce and maintain a sporting identity, and this in turn indicates a desire to maintain and develop activity and exercise engagement.

\subsection{Considering the process of activity involvement}

This theme illustrates how identity can change with physical activity involvement. Two subthemes make up this theme: (1) phases of activity, and (2) evolving identity.

\subsubsection{Phases of activity}

Physical activity involvement was established through phases. Three primary phases were identified during the patients involvement with physical actvitity. Pre activity - considered the time before activity is initated. During this time patients are dependent on staff and others to inform them of the activity, including potential benefits. In thinking about the future activity, they could be faced with uncertainty about what could happen and worries from past 
experiences. For those who took part previously, they may have different associations or more confidence. Within activity - this stage is associated with time when particpants are engaged with the physical activity setting from the moment when they enter the activity environment to the moment they exited the environment. Post activity - this considers times following activity and includes reflecting on the experiences of activity. Table 1 details how participants autonomy and identity is influenced and changed, and how patients may come to exit from the experience and the need for support during this phase.

\begin{tabular}{|c|c|c|c|c|}
\hline Phase & $\begin{array}{l}\text { Evolving } \\
\text { autonomy }\end{array}$ & Evolving Identity & Exiting activity & $\begin{array}{l}\text { External Phases of } \\
\text { Support }\end{array}$ \\
\hline $\begin{array}{l}\text { Pre- } \\
\text { activity }\end{array}$ & $\begin{array}{l}\text { Dependency } \\
\text { Patients depend } \\
\text { on support, } \\
\text { encouragement } \\
\text { and information } \\
\text { from others. } \\
\text { Uncertainty } \\
\text { Patients have } \\
\text { informing worries } \\
\text { about situation, } \\
\text { who will be there, } \\
\text { what will or could } \\
\text { happen and what } \\
\text { to expect from } \\
\text { activity. }\end{array}$ & $\begin{array}{l}\text { Existing identity } \\
\text { The patients are } \\
\text { defined by their } \\
\text { current condition, } \\
\text { their current } \\
\text { preoccupation } \\
\text { (illness, passivity). } \\
\text { Projected identity } \\
\text { They may have } \\
\text { anticipation about } \\
\text { who they could } \\
\text { become, or re- } \\
\text { establishing who } \\
\text { they were. }\end{array}$ & $\begin{array}{l}\text { Limited interest } \\
\text { Don't enjoy sport } \\
\text { or physical } \\
\text { activity } \\
\text { No support } \\
\text { Not enough } \\
\text { information, } \\
\text { motivation or } \\
\text { assistance from } \\
\text { others. } \\
\text { Uncertainty } \\
\text { Not enough } \\
\text { known about the } \\
\text { activity. Too } \\
\text { greater change } \\
\text { change attempted } \\
\text { or required is too } \\
\text { much. } \\
\text { Past experience } \\
\text { Negative } \\
\text { experiences may } \\
\text { predetermine } \\
\text { perception. }\end{array}$ & $\begin{array}{l}\text { The value of support } \\
\text { A known } \\
\text { environment } \\
\text { becomes a more } \\
\text { certain } \\
\text { environment, } \\
\text { important of } \\
\text { knowing the } \\
\text { people and the } \\
\text { facility. } \\
\text { Primary Role of } \\
\text { HCPs } \\
\text { Encouraging, } \\
\text { motivating, } \\
\text { educating and } \\
\text { directing patients. }\end{array}$ \\
\hline $\begin{array}{l}\text { Within } \\
\text { Activity }\end{array}$ & $\begin{array}{l}\text { Achievement } \\
\text { Going through the } \\
\text { process provides a } \\
\text { sense of } \\
\text { achievement and } \\
\text { perceived control. } \\
\text { Being heard } \\
\text { From taking part, } \\
\text { being heard and } \\
\text { listened to there is } \\
\text { value in a patient } \\
\text { being able to }\end{array}$ & $\begin{array}{l}\text { Distraction } \\
\text { Enabling activity } \\
\text { through removing } \\
\text { concerns. Sport } \\
\text { identity engulfs } \\
\text { existing identity. } \\
\text { Distraction can } \\
\text { enable or disable } \\
\text { identity change. } \\
\text { Positive Experience } \\
\text { Enthusiasm and }\end{array}$ & $\begin{array}{l}\text { Bad interaction or } \\
\text { experience } \\
\text { Existing from } \\
\text { getting to location, } \\
\text { within location or } \\
\text { following location } \\
\text { Uncertain } \\
\text { environment - } \\
\text { Experiences } \\
\text { become negative, } \\
\text { participation }\end{array}$ & $\begin{array}{l}\text { Distracting } \\
\text { Support within } \\
\text { sessions helps } \\
\text { provide a } \\
\text { distraction to } \\
\text { experiences } \\
\text { Listening - SMI } \\
\text { user control } \\
\text { content of } \\
\text { conversation. } \\
\text { Reflective }\end{array}$ \\
\hline
\end{tabular}




\begin{tabular}{|c|c|c|c|c|}
\hline Phase & $\begin{array}{l}\text { Evolving } \\
\text { autonomy }\end{array}$ & Evolving Identity & Exiting activity & $\begin{array}{l}\text { External Phases of } \\
\text { Support }\end{array}$ \\
\hline & $\begin{array}{l}\text { express } \\
\text { themselves. } \\
\text { Opportunity to be } \\
\text { heard. } \\
\text { Expression of self } \\
\text { Activity provides } \\
\text { a context to } \\
\text { express feelings } \\
\text { through } \\
\text { movement. }\end{array}$ & $\begin{array}{l}\text { Enjoyment of } \\
\text { activity draws } \\
\text { patient away from } \\
\text { existing identity. } \\
\text { Group Interaction } \\
\text { Identity of others } \\
\text { impacts on } \\
\text { patients. }\end{array}$ & ceases. & $\begin{array}{l}\text { questioning - } \\
\text { Provide change } \\
\text { for reflection and } \\
\text { evolving phase. } \\
\text { Social } \\
\text { Increasing } \\
\text { network of } \\
\text { support and } \\
\text { known } \\
\text { environment. }\end{array}$ \\
\hline $\begin{array}{l}\text { Post } \\
\text { activity }\end{array}$ & $\begin{array}{l}\text { Considering } \\
\text { experiences } \\
\text { Positive } \\
\text { experiences, } \\
\text { valued } \\
\text { friendships. } \\
\text { Developing } \\
\text { autonomy } \\
\text { confidence to do } \\
\text { more activity } \\
\text { Developing } \\
\text { independence } \\
\text { Through seeing } \\
\text { achievement, } \\
\text { acknowledging } \\
\text { possibilities } \\
\text { Development of } \\
\text { motivation } \\
\text { towards more } \\
\text { activity and other } \\
\text { global activities. } \\
\text { Reflecting } \\
\text { Modifying } \\
\text { existing } \\
\text { knowledge of } \\
\text { environment, } \\
\text { interaction and } \\
\text { ability. } \\
\text { Challenging } \\
\text { uncertainty and } \\
\text { unreliability of } \\
\text { new situations }\end{array}$ & $\begin{array}{l}\text { Reflections } \\
\text { Reflection within } \\
\text { self and with } \\
\text { others through } \\
\text { interaction. } \\
\text { Projected identity } \\
\text { is enforced. Past } \\
\text { identity is } \\
\text { remembered. } \\
\text { Reflective processes } \\
\text { Acceleration and } \\
\text { evolution of } \\
\text { identity. } \\
\text { Expanding identity } \\
\text { Identity impacts } \\
\text { on patients } \\
\text { outside the } \\
\text { exercise setting. } \\
\text { Becoming } \\
\text { Part of the identity } \\
\text { is incorporate into } \\
\text { self. }\end{array}$ & $\begin{array}{l}\text { Bad experiences } \\
\text { Experience or } \\
\text { interaction, } \\
\text { reaction to } \\
\text { experience } \\
\text { (increasing voices) } \\
\text { was negative. } \\
\text { Limited control } \\
\text { Was present and } \\
\text { process becomes } \\
\text { unsafe and } \\
\text { uncertain. }\end{array}$ & $\begin{array}{l}\text { Monitoring } \\
\text { experience } \\
\text { Evolving and } \\
\text { encouraging } \\
\text { activities and } \\
\text { transferring and } \\
\text { supporting other } \\
\text { engagement. } \\
\text { Listening and } \\
\text { valuing } \\
\text { Patient } \\
\text { expressions of } \\
\text { their experiences } \\
\text { are important as } \\
\text { they }\end{array}$ \\
\hline
\end{tabular}

Table 1. Illustrating three phases of physical activity involvement 


\subsubsection{The evolving identity}

From the above sub-theme it can be established that one primary goal of physical activity is to develop a patient's identity through physical activity and sport. Thus, physical activity can help the patient transfer from being someone who may consider community activities passively towards someone who is proactive towards activities. Alongside this the patient's existing identity is challenged through a number of key processes to become an evolved identity. Figure 1 provides an idea of how activity challenges a patient's existing identity and facilitates the evolution of identity.

\author{
Existing Identity \\ -Looking forward to \\ exercise \\ - Uncertainty \\ towards experience
}

\section{Evolved Identity}

-Looking forward to exercise

- Less uncertainty

- More confidence and courage

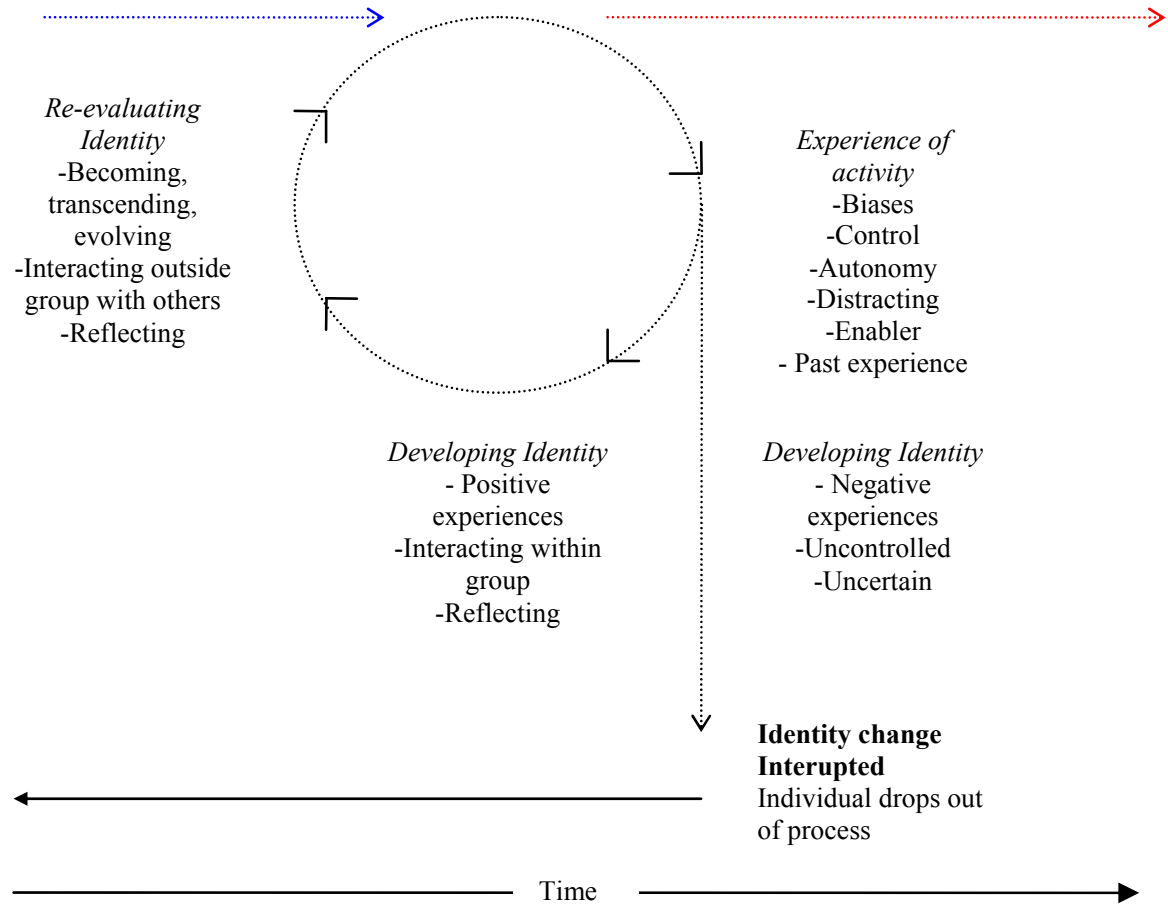

Fig. 1. The evolving identity cycle

The evolving identity cycle shows that the perception or experience of activity is vital in helping develop the patient's identity. The cycle demonstrates the challenges to identity that can exist before the activity has begun and during the activity. These challenges are illustrated by the barriers mentioned in section 4.2 and are clearly more significant in regard to the uptake of physical activity. Barriers are generated by worry, caused by an unknown 
or uncertain experience, and then again during activity where perceptual biases, ambiguous or negative interactions and inadequate support may act to prevent the patient embracing the experience. Following a negative experience the ability to change, evolve and adapt the patient's identity is likely to fail. Conversely, following a positive experience a patient is able to use interaction and reflection to transform their identity. A more positive cycle exists once the patient is able to consider the activity as more of a certain, safe and supported experience. This positive cycle is essential in supporting the maintenance of activity.

\section{Discussion}

Engagement in physical activity for patients with SMI requires careful consideration. Exploring the psychosocial experience of physical activity and exercise for patients with SMI has provided a useful understanding of the processes involved in initiating and maintaining activity, as well as establishing barriers and facilitators of activity. This information is well placed to inform both patients with SMI as well as those who have a support role such as health care professionals, carers, and family members. This discussion will look to summarise the barriers and facilitators of activity before turning attention to both psychosocial phases of activity and the evolution of a patient's identity.

\subsection{Initiating activity}

Two of the biggest physical barriers for patients with SMI included being too tired to exercise or being unable to exercise because of their illness (Ussher et al., 2007). Stability in symptoms of illness is a good precursor to initating activity (Carless, 2007). Part of this was a direct result of their medication and its side effects (Gorczynski \& Faulkner, 2011; Roberts \& Bailey, 2011). Another consistent and challenging barrier to activity participation was the location of the activity and the costs involved with the activity. The problem of finances is compounded by the problem of frequent unemployment and dependence on benefits (Hodgson et al., 2011). Carless and Douglass (2008a) suggest that tangible support is required for patients to address these barriers.

There are difficulties patients with SMI can initially experience that are not experienced long term, such as an unknown setting, experiences and interactions. These aspects of engaging in physical activity challenge the patients self-esteem, courage, autonomy and motivation (Butterly et al., 2006; Soundy, 2007). Being able to attend activity sessions provides an opportunity to become more independent (Shiner et al., 2008). However, beginning activity can be difficult as patients may have a lack of initiative (Roberts \& Bailey, 2011). Patients need to perceive what the experience will involve because not being sure of what is required of them during exercise, being self-conscious, feeling unsafe, and being afraid to get injured are common barriers to activity (Gorczynski \& Faulkner, 2011; Ussher et al., 2007). In addition, problems can be created in new and uncertain social environments where patients may be more sensitive to interactions and experiences (Soundy, 2007).

The benefit of activity can be simply undertaking a new situation, creating a sense of meaning or purpose and an opportunity to break old routines. Positive experiences before the activity (achievement, positive memories) help provide more enthausiasm (Carless, 2007). The structure of programs before delivery should consider certain aspects, such as being informative (Carless \& Douglas, 2008a), providing users with a program that meets their own pace (Gorczynski \& Faulkner, 2011), and has in place a good motivational leader 
(Richardson, 2005). Aspects such as the journey to the new environment can be something to be received positively (Crone, 2007). Being able to do something that can add to or change their lifestyle and routine was highly valuable to patients with SMI. Physical benefits were also present and included the general effects of participating in activity like weight loss (Fogarty \& Happell, 2005; Chiverton et al., 2007) or indeed just having knowledge of the benefits of a more healthy lifestyle (Tetlie et al., 2009; McDevitt et al., 2006).

Before activity is initiated, feelings of isolation can prevent activity engagement (Hodgson et al., 2011; Roberts \& Bailey, 2011). A good support network is required to combat the experience many users have of social isolation, marginalisation and stigmatisation (Ellis et al., 2007; Gorczynski \& Faulkner, 2011). Patients must be carefully supported from the initial interaction with services. The right kind of individualised support service that acknowledges patients' preferences and experiences is required to achieve a more successful adoption of exercise. Support is needed in different ways including encouragement, finances and listening (Carless \& Douglas, 2008a). It should also be provided by known mental health professionals (Hodgson et al., 2011).

\subsection{Maintaining activity}

Autonomy for the activity was slowly provided for users as they took responsibility for attendance (Carless \& Douglas, 2004). A sense of autonomy and achievement and purpose is obtained from activity (Crone, 2007). Prolonged engagement is enhanced once a sense of acheivement, purpose and enjoyment is obtained.

Psychologically being able to experience achievement, to realise goals, to experience a sense of control, to have a distraction from negative aspects of the illness provides a basis for enjoying activity. The exercise group provides a setting that empowered the patient to share information about them self (Faulkner \& Sparkes, 1999). A postive and enjoyable experience can provide an important part of conversation within and outside the exercise settings (Carless \& Douglas, 2004).

Much of the appreciation from patients who undertake an activity can focus on the routine nature of the activity; this enhances rapport and relationships and the enjoyment of a meaningful activity (Marzolini et al., 2009). Support is required once activity begins: one-toone support (from staff and by other users or patients) can provide an important distraction and encouragement for patients (Carless \& Douglas, 2008a; Crone \& Stembrige, 2007; Roberts \& Bailey, 2011; Soundy, 2007). There is an important role for instructors within this to provide appropriate support, as Richardson et al., (2005) state "Enthusiastic, knowledgeable, and supportive exercise leaders are as important as the actual exercise prescription itself" (page 327). Accordingly, social support provides certainty and confidence when engaging in new environments. However, it is still possible for patients to experience or percieve threats or problems with the environment such as anxiety attacks (Carless, 2008). Providing a safe, welcoming and friendly environment is needed to acheive adherence over the long term, where some inconsistency in attendence can be expected (Soundy, 2007). Indeed a caring and relaxed environment can help patients enjoy the experience (Carless \& Douglass, 2004). A chain of supportive networks is needed from identifying a program of activity to maintaining that program of activity. Some of the most positive results of physical activity are achieved in inpatient settings where there are greater levels of day-to-day support (Ellis et al., 2007). The attributes of those supporting the intervention are essential as a faciliator to continued activity (Chiverton et al., 2007; Soundy, 2007); conversely, the stigma associated 
with mental illness from patients working in exercise settings may be a barrier (Crone \& Stembrigdge, 2007). Group based activities are often associated with higher levels of adherence than patient programs. One of the reasons given for this is because group activities that are supervised can eliminate the avoidable barriers to exercise (Marzolini et al., 2009). In addition, group activities promote social interaction and contribute to a more enjoyable experience (Fogarty and Happell, 2005; Holley et al., 2011). One role of activity is to create and maintain supportive social relationships (McDevitt et al., 2006). Thus, being able to provide and maintain a social network within the activity setting is important for prolonged engagement. The utilization of social networking devices may be a way to encourage and develop patient's social expression, unity, support and identity (Killackey et al., 2011). Conversely, a limited network or isolated support can create reliance and dependency on health care professionals which can have negative effects (Faulkner \& Sparkes, 1999; Soundy, 2007).

\subsection{The creation and evolution of a social identity}

One of the biggest challenges when working with patients with SMI is how to maintain the users engagement with an activity program (Hodgson et al., 2011). Programs that use behaviour modification principle, like social support or goal setting are more effective than more simple programs (Richardson et al., 2005). Following the support that is gained early in promoting activity further development of different and sustainable relationships are required and obtained in the group setting. This greater range of relationships means patients have less reliance on a smaller support network (Soundy, 2007). Successful achievement within the exercise setting helps provide patients with an increased sense of self-efficacy (Richardson et al., 2005). Indeed, engagement in exercise increases a participant's confidence in social settings and provides them with a sense of a social identity which enables them to further engage with fellow exercise participants.

Belonging to a group and attending physical activity sessions provides users with a sense of purpose and creates a social confidence that can then be transferred to new settings (Hodgson et al., 2011). A sense of belonging also influences how patients redefine their selfidentity (Shea, 2009). Exercise and physical activity in a community setting provides a setting that can help promote a sense of belonging and therefore provides an excellent opportunity for refining their self identity (Shea, 2009). For some users this may be a sense of returning to who they used to be and or towards normality (Carless \& Douglass, 2008b).

\section{Implications for health care professionals}

A network of supportive relationships that are sustainable is required in order for successful participation in exercise. Health care professionals need to consider the provision of support from introducing the patient to the idea of becoming more physically active through to introducing patients into a new setting. Clearly, there is also a need for health care professionals to be able to recognise the different dimensions (informational, tangible, emotional and esteem) of socal support (Carless \& Douglas, 2008a).

It is essential that patients feel able to talk to others about negative experiences and interactions; this provision within the mental health setting and community setting is needed to address the identified barriers to activity. We urge HCPs to invest time in listening to and sharing in patients' experiences. Capturing changes in social support that 
occurs through engagement in exercise and physical activity may be best achieved by using existing inventories; for example, Sarason et al., (1987) provide a short form inventory that considers the social support that others provide in an individual's environment.

The psychological changes during exercise may be best captured by considering how patients confidence, self-efficacy and self-identity is challenged and shaped through the process of exercise, from intial to sustained engagement in exercise. The means of assessing these may be made through observations, informal conversation or through non-taxing inventories; for example, Bandura (1997) proposes a way to develop an inventory tool for self-efficacy. Improvement in any of these psychological domains will have a clear impact on the patients lifestyle and well-being.

\section{Future recommendations}

There is a need for research to consider assessing how interventions can influence confidence, self-identity, self-efficacy and social support following physical activity interventions. It is important that further research is able to distingush the best tools that can be used to assess such effects. More specifically, we suggest there is a need for future research to consider each of these psychosocial variables in greater detail. For example, in regards to social support, reseach could explore the most effective ways to capture change in the network and structure of patients' support. In addition to this, research could establish whether perceived availability of support and/or enacted (received) support exerts positive effects upon outcomes.

\section{Conclusion}

The development of a social identity is a natural and very beneficial aspect of undertaking a physical activity or sports based group. There are barriers that prevent initiation to activity as well as barriers that exist once activity has begun. Physical activity and sport has the potential to break down the barriers and help create a new social identity for the user. Undertaking activity helps develop the user's confidence and courage and through realising a new and changed identity users appear more able to engage with community based physical activity.

\section{Acknowledgments}

Thanks to Dr D Carless for providing references for supporting the search for articles and for his extensive work within this field of research.

\section{References}

Atkins, S., Lewin, S., Smith, H., Engel, M., Fretheim, A., Volmink, J. (2008). Conducting a meta-ethnography of qualitative literature: Lessons learnt. BMC Medical Research Methodology, 8, pp. (1-10).

Bandura, A. (1997). Self-efficacy: The exercise of control. New York: Freeman.

Britten, N., Campbell, R., Pope, C., Donovan, J., Morgan, M., Pill, R. (2002). Using meta ethnography to synthesise qualitative research: A worked example. Journal of Health Services Research Policy, 7, pp. (209-215). 
Campbell, R., Pound, P., Pope, C., Britten, N., Pill, R., Morgan, M., Donovan, J. (2003). Evaluating meta-ethnography: A synthesis of qualitative research on lay experiences of diabetes and diabetes care. Social Science $\mathcal{E}$ Medicine, 56, pp. (671684).

Carless, D. (2008). Narrative, identity and recovery from serious mental illness: A life history of a runner. Qualitative Research in Psychology, 5, pp. (233-248).

Carless, D. (2007). Phases in physical activity initiation and maintenance among men with serious mental illness. International Journal of Mental Health Promotion, 9, pp. (17-27).

Carless, D., Douglas, K. (2004). A gold programme for people with severe and enduring mental health problems. Journal of Mental Health Promotion, 3, pp. (23-39).

Carless, D., Douglas, K. (2008a). Social support for and through exercise and sport in a sample of men with serious mental illness. Issues in Mental Health Nursing, 29, pp. (1179-1199).

Carless, D., Douglass, K. (2008b). The role of sport and exercise in recovery from serious mental illness: Two case studies. International Journal of Men's Health, 7, pp. (137156).

Carless, D., Sparkes, A. C. (2008). The physical activity experiences of men with serious mental illness: three short stories. Psychology of Sport and Exercise, 9, pp. (191-210).

Carter-Morris, P., Faulkner, G. (2003). A football project for mental health service users. Journal of Mental Health Promotion, 2, pp. (24-30).

Crone, D. (2007). Walking back to health: A qualitative investigation into service users' experiences of a walking project. Issues in Mental Health Nursing, 28, pp. (167-183).

Crone, D., \& Stembridge, L. (2007). Getting a move on. Mental Health Today, April, pp (3032).

Doyle, L. H. (2003). Synthesis through meta-ethnography: Paradoxes, enhacements and possibilities. Qualitative Research, 3, pp. (321-344).

Ellis, N., Crone, D., Davey, R., \& Grogan, S. (2007). Exercise interventions as an adjunct therapy for psychosis: a critical review. British Journal of Clinical Psychology, 46, pp. (95-111).

Hodgson, M. H., McCulloch, H. P., Fox, K. R. (2011). The experiences of people with severe and enduring metnal illness engaged in a physical activity programme integrated into the mental health service. Mental Health and Physical Activity, 4, pp. (23-29).

Holley, J., Crone, D., Tyson, P., \& Lovell, G. (2011). The effects of physical activity on psycholgoicla well-being for those with schizophrenia: A systematic review. Biritsh Journal of Clinical Psychology, 50: pp. (84-105).

Killackey, E., Anda, A. L., Gibs, M., Alvarez-Jimenez, M., Thompson, A., Sun, P., \& Baksheev, G. N. (2011). Using internet enabled mobile devices and soical networking techniolgies to promote execise as an inervention for young first episode psychosis patietns. BMC Psychiatry,11, pp. (80).

Malpass, A., Shaw, A., Sharp, D., Walter, F., Feder, G., Ridd, M., \& Kessler, D. (2009). "Medication Career" or "Moral Career"? The two sides of managing antidepressants: A meta-ethnography of patients' experience of antidepressants. Social Science and Medicine, 68, pp. (154-168).

McDevitt, J., Snyder, M., Miller, A., \& Wilbur, J. (2006). Perceptions of barriers and benefits to physical activity among outpatients in psychiatric rehabiliation. Journal of Nursing Scholarship, 38, pp. (50-55). 
Noblit, G.W., Hare, R.D. (1988). Meta-ethnography: Synthesising qualitative studies. New York: Sage

Faulkner, G and Biddle, S. (1999) Exercise as an adjunct treatment for schizophrenia: A review of the literature. Journal of Mental Health, 8, pp. (441-457).

Faulkner, G., Soundy, A. A., \& Lloyd, K. (2003). Schizophrenia and weight management: a systematic review of interventions to control weight. Acta Psychiatrica Scandinavica, 108, pp. (324-332).

Faulkner, G., and Sparkes, A. (1999). Exercise as therapy for schizophrenia: an ethnographic study. Journal of Sport and Exercise Psychology, 21, pp. (52-69).

Gorczynski, P., \& Faulkner, G. (2009). Exercise therapy for schizophrenia. Cochrane database of systematic reviews, 2010. Issue 5. Art. No. CD004412.

DOI: 10.1002/14651858.CD004412.pub2.

Raine, P., Truman, C., Southerst, A. (2002). The development of a community gym for people with mental health problems: influences on psychological accessibility. Journal of Mental Health, 11, pp. (43-53).

Richardson, C. R., Faulkner, G., McDevitt, J., Skrinar, G. S., Hutchinson, D. S., Piette, J. D. (2005). Integrating physical activity into mental health services for persons with serious mental illness. Psychiatric Services, 56, pp. (324-331).

Roberts, S. H., \& Bailey, J. E. (2010). Incentives and barriers to lifestyle interventions for poele with severe mental illness; a nrrative sytnthesis of quantitative, qulaitative and mixed methods studies. Journal of Advanced Nursing, 67, pp. (690-708).

Sarason, I. G., Sarason, B. R., Shearin, E. N., Pierce, G. R. (1987). A brief measure of soical support: practical and theoretical implications. Journal of Soical and Personal Relationships, 4, pp. (497-510).

Shea, J. M. (2009). Coming back to normal: the process of self-recovery in those with schizophrenia. Journal of the American Psychiatric Nurses Assoication, 16, pp. (43-51).

Shiner, B., Whitley, R., Van Citters, A. D., Pratt, S. I., Bartels, S. J. (2008). Learning what matters for patients: qualitative evaluation of a health promotion program for those with serious mental illness. Health Promotion International, 23, pp. (275-282).

Soundy, A. (2007). Understanding physical activity in individuals with severe mental illness. A doctoral thesis. University of Exeter.

Soundy, A., Faulkner, G., Taylor, A. (2007). Exploring Variability and Perceptions of Lifestyle Physical Activity Among Individuals with Severe and Enduring Mental Health Problems: A Qualitative Study. Journal of Mental Health, 16, pp. (493-503).

Soundy, A., Smith, B., Dawes, H., Pall, H., Gimbrere, K., Ramsay, J. (2011). Patient's expression of hope in three neurogloical conditions; a meta-ethnography. Health Psychology Review, ifirst, 1-25. DOI: 10.1080/17437199.2011.568856.

Tetlie, T., Heimsnes, M., \& Almvi, R. (2009). Using exercise to treat patients with severe mental illness: how and why? Journal of Psychsocal Nursing and Mental Health Services, 47, pp. (32-40).

Ussher, M., Stanbury, L., Cheeseman, V., Faulkner, G. (2007). Physicl activity preferences and perceived barriers to activity among persons with severe mental illness in the united kingdom. Psychiatric Services, 58, pp. (405-408).

Van Mannen, J., Manning, P.K., \& Miller, M.L. (1988). Series editors' introduction. In G.W. Noblit \& R.D. Hare (Eds.), Meta-ethnography: Synthesising qualitative studies pp. (5-6). London: Sage 
Weed, M. (2008). A potential method for the interpretive synthesis of qualitative research: Issues in the development of meta-interpretation. International Journal of Social Research Methodology, 11, pp. (13-28). 


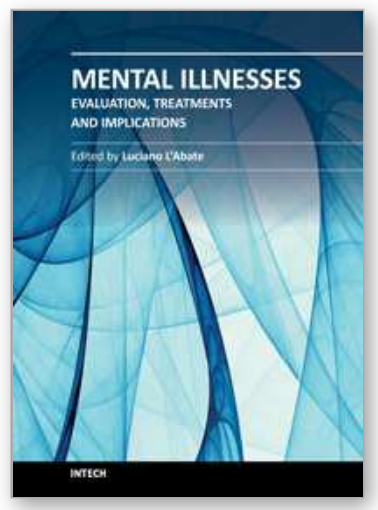

\author{
Mental IIInesses - Evaluation, Treatments and Implications \\ Edited by Prof. Luciano LAbate
}

ISBN 978-953-307-645-4

Hard cover, 476 pages

Publisher InTech

Published online 13, January, 2012

Published in print edition January, 2012

In the book "Mental Illnesses - Evaluation, Treatments and Implications" attention is focused on background factors underlying mental illness. It is crucial that mental illness be evaluated thoroughly if we want to understand its nature, predict its long-term outcome, and treat it with specific rather than generic treatment, such as pharmacotherapy for instance. Additionally, community-wide and cognitive-behavioral approaches need to be combined to decrease the severity of symptoms of mental illness. Unfortunately, those who should profit the most by combination of treatments, often times refuse treatment or show poor adherence to treatment maintenance. Most importantly, what are the implications of the above for the mental health community? Mental illness cannot be treated with one single form of treatment. Combined individual, community, and socially-oriented treatments, including recent distance-writing technologies will hopefully allow a more integrated approach to decrease mental illness world-wide.

\title{
How to reference
}

In order to correctly reference this scholarly work, feel free to copy and paste the following:

Andrew Soundy, Thomas Kingstone and Pete Coffee (2012). Understanding the Psychosocial Processes of Physical Activity for Individuals with Severe Mental Illness: A Meta-Ethnography, Mental Illnesses - Evaluation, Treatments and Implications, Prof. Luciano LAbate (Ed.), ISBN: 978-953-307-645-4, InTech, Available from: http://www.intechopen.com/books/mental-illnesses-evaluation-treatments-and-implications/understanding-thepsychosocial-processes-of-physical-activity-for-individuals-with-severe-mental-ill

\section{INTECH}

open science | open minds

\section{InTech Europe}

University Campus STeP Ri

Slavka Krautzeka 83/A

51000 Rijeka, Croatia

Phone: +385 (51) 770447

Fax: +385 (51) 686166

www.intechopen.com

\section{InTech China}

Unit 405, Office Block, Hotel Equatorial Shanghai

No.65, Yan An Road (West), Shanghai, 200040, China

中国上海市延安西路 65 号上海国际贵都大饭店办公楼 405 单元

Phone: +86-21-62489820

Fax: $+86-21-62489821$ 
(C) 2012 The Author(s). Licensee IntechOpen. This is an open access article distributed under the terms of the Creative Commons Attribution 3.0 License, which permits unrestricted use, distribution, and reproduction in any medium, provided the original work is properly cited. 